\title{
Pseudomonas spp. as models for plant-microbe interactions
}

\author{
Ramakrishnan Sitaraman * \\ Department of Biotechnology, TERI University, New Delhi, India
}

Keywords: Pseudomonas, microbiota, phytomicrobiome, plant-microbe interactions, phospholipase, quorum sensing, type VI secretion, lipopeptide

\section{The Phytomicrobiome in Context}

As is the case with other multicellular eukaryotes, plants are colonized by large numbers of unicellular microorganisms. They may be free-living commensals, epiphytes, symbionts (endophytes), or obligate parasites. The plant holobiont is in effect an ecosystem, and it is of interest to know how this assemblage is established and maintained, and reacts to both biotic and abiotic cues. The current view, initially elaborated in the context of coral-dwelling microbial communites, is that the multicellular organism is more inclusively described by the term "holobiont" that includes associated microbiota, and is a valid unit of natural selection (Rosenberg et al., 2007). The holobiont then, is often dependent on its microbiota for crucial functions, drastic imbalances in which, termed dysbiosis, are thought to lead to compromised or deficient functioning.

The association of plants with microbes is phylogenetically ancient, going back to the macroalgae (Marshall et al., 2006). The role of the microbiota of plants, collectively termed the "phytomicrobiome," in their overall life cycle is now under investigation, close on the heels of more extensive studies on animal, especially human, microbiota. The development of Arabidopsis thaliana (thale cress) and Brachypodium distachyon (purple false brome) as model systems for dicotyledonous and monocotyledonous plants respectively, and the availability of genome databases for Pseudomonads (Winsor et al., 2011) and plants (Duvick et al., 2008) indicate that the potential for both hypothesis-based and discovery science are indeed great.

The assembly, development and maintenance of the plant holobiont is not possible without an

Reviewed by:

Vittorio Venturi,

International Centre for Genetic Engineering and Biotechnology, Italy

*Correspondence: Ramakrishnan Sitaraman, minraj@gmail.com

Specialty section: This article was submitted to Plant Biotic Interactions, a section of the journal Frontiers in Plant Science

Received: 01 April 2015 Accepted: 11 September 2015 Published: 29 September 2015

Citation:

Sitaraman R (2015) Pseudomonas spp. as models for plant-microbe interactions. Front. Plant Sci. 6:787.

doi: 10.3389/fp/s.2015.00787 exchange and sensing of, and responses to, biomolecular cues between its constituents. Within this overall theme, we focus on a few recently discovered, novel inter- and intra-species interactions of some Pseudomonas spp., indicating their utility as model systems, and highlighting some previously unforeseen mechanisms that could have a bearing on plant-phytomicrobiome interactions. Note that, for purposes of this article, we use the word "signaling" to refer generically to the sensing and response of organisms to environmental cues of both biotic and abiotic origins.

\section{Some Aspects of the Social Biology of Pseudomonas spp.}

The genus Pseudomonas is the most numerous among the cataloged genera of Gram-negative bacteria (Gomila et al., 2015). The ubiquity and metabolic versatility of this genus allows it to colonize a wide range of natural habitats and adopt a variety of lifestyles. Pseudomonas spp. have been isolated from each of the ecological niches within a plant as stated earlier (for a compilation, see Table 1 of Mercado-Blanco and Bakker, 2007). Their known ability to interact with and influence other bacteria, fungi, and multicellular organisms in a variety of biological contexts, and the availability of experimental tools for their genetic manipulation, should greatly facilitate the translation of knowledge for a wide range of practical applications. 
At the outset, it is worth recalling that strains of $P$. putida and $P$. aeruginosa were the first living, genetically modified organisms to be patented for a specific application (biodegradation of petrochemicals-camphor, octane, salicylate, and naphthalene)-truly heralding the modern era of genetically modified organisms (Chakrabarty, 1981). The genus Pseudomonas is behaviorally very versatile, with free-living as well as parasitic forms capable of colonizing a wide variety of host organisms and ecological niches within hosts. For example, $P$. aeruginosa $(\mathrm{PA})$ is a free-living soil bacterium that is also an opportunistic pathogen of both plants and animals, $P$. syringiae (PS) is an opportunistic plant pathogen, $P$. putida (PP) has been extensively used in bioremediation for its ability to utilize a wide range of hydrocarbons as carbon sources, and both $P$. putida and $P$. fluorescens (PF) are promising growth-promoting and biocontrol agents.

In order to understand the role of the bacterial component of the phytomicrobiome in plant physiology, the functional analysis of bacteria colonizing multiple ecological niches provided by the plant-the roots (rhizosphere), leaves (phyllosphere), surfaces (ectosphere), and tissues (endosphere) - needs to be undertaken, ideally in situ and over the several developmental stages of the plant. This is an understandably formidable task, and the utility of a model bacterium in this context is apparent. From a bacterial viewpoint, it has to sense the presence of, and stimuli from, potential hosts as well as competitors (of the same or different species), strategize in a manner that allows it to reach the host, survive competition, and colonize, gain access to resources, and persist for a reasonable length of time in the face of perturbations. The establishment and resilience of the plant-microbe interaction is therefore dependent on the exchange and sensing of a variety of signals by both types of partners, often simultaneously, and combinatorially.

\section{Bacterial Quorum Sensing and Inter-species Competition}

Pseudomonas spp. possess quorum-sensing (QS) systems that synthesize and sense hormone-like messages of diverse origins in their immediate environment. QS systems are often linked with other regulons, leading to different phenotypes (for a review, see Venturi, 2006). For example, PP produces cyclic lipopeptide surfactants putisolvin I and II, that are under the control of QS and disrupt biofilms (Kuiper et al., 2004; Dubern et al., 2006). Interestingly, this can happen not only at the stationary phase, but also stochastically in the early stages of growth resulting in swarming motility (Cárcamo-Oyarce et al., 2015), promoting colonization of fresh surfaces. Other putisolvin-like lipopeptides of PP have been found to exhibit lytic activity against the zoospores of the fungal pathogen Phytophthora capsici zoospores in vitro, inhibit growth of the fungal pathogens Botrytis cinerea and Rhizoctonia solani in addition to being involved in swarming motility (Kruijt et al., 2009). In more general terms such interactions could contribute to the overall composition of the phytomicrobiome by modifying its diversity, and contribute to its resilience to perturbation by invaders.

Plant growth promotion effects of Pseudomonas spp. may also be under QS control, as was demonstrated in the case of
QS-controlled production of an $N$-acyl-L-homoserine lactone (AHL), cyclic dipeptides and their derivative diketopiperazines (DKPs) by PA. Exposure of A. thaliana seedlings to 3-oxoC12-AHL produced by the LasI AHL synthase causes growth inhibition of the primary root, while DKP stimulated the growth of lateral roots (Ortiz-Castro et al., 2011). The presence of orphan AHL transcriptional regulators such as QscR in PA that lack a cognate AHL synthase and bind with relaxed specificity to both endogenously and exogenously produced AHLs adds another layer of complexity to plant-phytomicrobiota interactions (for a recent and detailed review, see Chugani and Greenberg, 2014). Likewise, pseudomonads as well as other plant-associated bacteria have been found to encode a unique family of orphan (or solo) AHL transcriptional regulators that are uniquely responsive to unknown plant and/or bacterial signal molecules (Patel et al., 2013).

That one component of the microbiota may influence another indirectly by modulating host signals and responses has been dramatically demonstrated recently in both plant and animal contexts. PS pathovar tomato (PSt) infection of Arabidoposis thaliana leaves induces the plant enzyme phospholipase Db1 (PLDb1) that is a negative regulator of the salicylic aciddependent resistance to PS, but is a positive regulator of the jasmonic acid-dependent resistance to the fungal pathogen Botrytis cinerea. Even more interestingly, infection with an avirulent PSt strain that expresses the effector AvrRpt2 secreted by the type III secretion system can also lead to resistance against virulent Pst that does not express AvrRpt2 (Zhao et al., 2013). Thus, indirect microbial modulation of the host can cause subtle, even strain-level, shifts in the composition of microbiota, depending on the temporal sequence of host colonization. In what may well be a case of convergent survival strategies, PA infection of airways in human patients of cystic fibrosis induces airway cells of the airway epithelium to produce secretory phosopholipase A2, which is bactericidal for Gram-positive bacteria such as Staphylococcus aureus but relatively less so for PA (Pernet et al., 2014). This effectively allows PA to proliferate at the expense of $S$. aureus.

\section{Identification of Putative Type VI Effectors in Plant-associated Pseudomonas spp.}

The ability of PA to infect both plant and animal hosts, and the identification of a common set of virulence determinants during plant and animal infections (Rahme et al., 1997, 2000), along with genome sequence information can be exploited to identify potential effectors and predict putative mechanisms of interaction with the host plant in the context of other Pseudomonas spp. Recent, extensive analyses of the A. thalianaassociated microbiota indicate that Pseudomonas spp. are preferentially enriched in the endophytic compartment of the plant, as compared to the rhizosphere (Bulgarelli et al., 2012; Lundberg et al., 2012). Therefore, the identification of conserved effectors within the pseudomonad lineage can be used as a starting point to probe plant-microbe interactions. The type VI secretion systems (T6SS) merit special attention in this regard as they are widespread among diverse Gram-negative bacteria, both pathogenic and non-pathogenic including Pseudomonas 
TABLE 1 | A representative list of putative effectors potentially targeting plant cells and encoded by T6SS in plant-associated Pseudomonas spp.

\begin{tabular}{|c|c|c|c|c|c|}
\hline $\begin{array}{l}\text { Effector molecule(s) } \\
\text { of } P \text {. aeruginosa }\end{array}$ & $\begin{array}{l}\text { Locus tag/Strain } \\
\text { of PA }\end{array}$ & Known function and context in PA & $\begin{array}{l}\text { Reference(s) for } \\
\text { known functions }\end{array}$ & $\begin{array}{l}\text { Plant-associated } \\
\text { Pseudomonas spp. }\end{array}$ & Ortholog locus tag \\
\hline \multirow[t]{2}{*}{ Phospholipase D (PldB) } & PA5089/PAO1 & $\begin{array}{l}\text { Encoded by the H3-T6SS. Elimination } \\
\text { of compteting bacteria. Promoting PA } \\
\text { internalization by host (human) }\end{array}$ & Jiang et al., 2014 & $\begin{array}{l}\text { Pseudomonas sp. UW4 } \\
\text { P. syringae pv. Phaseolicola } \\
\text { 1448A (pathogen) }\end{array}$ & $\begin{array}{l}\text { PputUW4_03278 } \\
\text { PSPPH_0117 }\end{array}$ \\
\hline & & epithelial cells & & $\begin{array}{l}\text { P. syringae pv. Syringae } \\
\text { B728a (pathogen) }\end{array}$ & Psyr_4970 \\
\hline $\begin{array}{l}\text { Valine-glycine repeat } \\
\text { protein (VgrG2b) }\end{array}$ & PA0262/PAO1 & $\begin{array}{l}\text { Encoded by the H2-T6SS. Delivered } \\
\text { into host (human) epithelial cells, } \\
\text { promotes microtubule-mediated PA } \\
\text { internalization by direct interaction } \\
\text { with microtubules }\end{array}$ & Sana et al., 2015 & $\begin{array}{l}\text { P. syringae pv. syringae } \\
\text { B728a } \\
\text { Pseudomonas sp. UW4 } \\
\text { P. putida F1 (orthologs also } \\
\text { present in strains HB3267, } \\
\text { KT2440, H8234, ND6, } \\
\text { GB-1, NBRC 14164, W619 } \\
\text { and DOT-T1E) }\end{array}$ & $\begin{array}{l}\text { Psyr_4080 } \\
\text { PputUW4_03083 } \\
\text { Pput_2117 }\end{array}$ \\
\hline
\end{tabular}

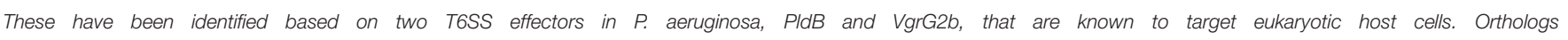

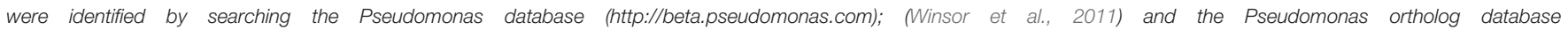
(http://pseudoluge.pseudomonas.com/pseudoluge/named/list/search?field=locus_tag\&value=PCHL3084_RS00035); (Whiteside et al., 2013).

spp. (Barret et al., 2011), and can potentially deploy effectors targeting both prokaryotic and eukaryotic cells (Jiang et al., 2014). Two effectors secreted by T6SS in PA that are known to target host cells, and their orthologs identified in plant-associated Pseudomonas spp. are listed in Table 1. The functionality of these effectors on plant cells, if verified, can provide important information about the assembly and disruption of bacterial communities, as well as their interaction with the host plant.

\section{Conclusions and Future Directions}

The foregoing account suggests new lines of inquiry into the signals that drive the formation and maintenance of the plant microbiota. Can systemic effects on the host and/or microbiota be mediated by diffusible signals produced in one part of the plant? If so, over what distances do these effects extend, and how are they mediated? What is the role of conserved and functional T6SS effectors in diverse plant-bacteria associations that range from commensalism to symbiosis? In the effort to understand the relative contribution of different components of the microbiota to the plant holobiont, it may be remembered that abundance alone may not truly reflect the relative importance of the species/strain in question. Numerically less abundant species could be key players within the microbiota, assuming the role of "keystone" species, as has been suggested earlier (Saraswati and Sitaraman, 2014).

A potential limitation in reliance on Gram-negative pseudomonads as model systems is that their relative importance may depend on environmental conditions. For example,
Pseudomonas spp. may be an important disease-suppressive agent in a moist and temperate environment in the Netherlands (Mendes et al., 2011), whereas the Gram-positive Bacillus spp. contribute to disease suppression in Egypt, a more arid zone (Köberl et al., 2011). Over reliance on Pseudomonas spp. as models could therefore potentially overlook unique interactions and mechanisms operative over large geographical areas and ecological zones. Also to be remembered is that most studies of microbiota (plant or animal) focus on the bacterial component alone, and the role of fungi and archaea is less studied and understood.

The microbiota of multicellular organisms, whether plant or animal, present a case wherein simultaneous and combinatorial interactions have to be identified, and their relative importance determined. To this end, the identification of effectors and the delineation of mechanisms of interaction are required. The predictive and inferential value of Pseudomonas spp.-based models that can be probed with conventional as well as highthroughput methods is therefore undeniable, and insights so gained have immense potential to inform and refine our efforts to dissect the mechanistic bases of interactions taking place in the plant holobiont.

\section{Acknowledgments}

This paper is dedicated to my parents, Mr. G. Sitaraman and Mrs. Indu Bala, for their unwavering encouragement and support of my studies. Dr. Jay Ram Lamichhane of INRA, France is thanked for a critical comment on the paper. The publication of this article has been facilitated by the grant of a full waiver of publishing fees by Frontiers. No funding was received for this work. 


\section{References}

Barret, M., Egan, F., Fargier, E., Morrissey, J. P., and O'Gara, F. (2011). Genomic analysis of the type VI secretion systems in Pseudomonas spp.: novel clusters and putative effectors uncovered. Microbiology 157, 1726-1739. doi: 10.1099/mic.0.048645-0

Bulgarelli, D., Rott, M., Schlaeppi, K., Ver Loren van Themaat, E., Ahmadinejad, N., Assenza, F., Rauf, P., et al. (2012). Revealing structure and assembly cues for Arabidopsis root-inhabiting bacterial microbiota. Nature 488, 91-95. doi: 10.1038 /nature 11336

Cárcamo-Oyarce, G., Lumjiaktase, P., Kümmerli, R., and Eberl, L. (2015). Quorum sensing triggers the stochastic escape of individual cells from Pseudomonas putida biofilms. Nat. Commun. 6, 5945. doi: 10.1038/ncomms6945

Chakrabarty, A. M. (1981). Microorganisms Having Multiple Compatible Degradative Energy-generating Plasmids and Preparation Thereof. Google Patents. Available online at: http://www.google.co.in/patents/US4259444

Chugani, S., and Greenberg, E. P. (2014). An evolving perspective on the Pseudomonas aeruginosa orphan quorum sensing regulator QscR. Front Cell Infect Microbiol 4:152. doi: 10.3389/fcimb.2014.00152

Dubern, J.-F., Lugtenberg, B. J. J., and Bloemberg, G. V. (2006). The ppuI-rsaLppuR quorum-sensing system regulates biofilm formation of Pseudomonas putida PCL1445 by controlling biosynthesis of the cyclic lipopeptides putisolvins I and II. J. Bacteriol. 188, 2898-2906. doi: 10.1128/JB.188.8.28982906.2006

Duvick, J., Fu, A., Muppirala, U., Sabharwal, M., Wilkerson, M. D., Lawrence, C. J., et al. (2008). PlantGDB: a resource for comparative plant genomics. Nucleic Acids Res. 36, D959-D965. doi: 10.1093/nar/gkm1041

Gomila, M., Peña, A., Mulet, M. M., Lalucat, J., and García-Valdés, E. (2015). Phylogenomics and systematics in Pseudomonas. Front. Microbiol. 6:214. doi: 10.3389/fmicb.2015.00214

Jiang, F., Waterfield, N. R., Yang, J., Yang, G., and Jin, Q. (2014). A Pseudomonas aeruginosa type VI secretion phospholipase D effector targets both prokaryotic and eukaryotic cells. Cell Host Microbe 15, 600-610. doi: 10.1016/j.chom.2014.04.010

Köberl, M., Müller, H., Ramadan, E. M., and Berg, G. (2011). Desert farming benefits from microbial potential in arid soils and promotes diversity and plant health. PLoS ONE 6:e24452. doi: 10.1371/journal.pone.0024452

Kruijt, M., Tran, H., and Raaijmakers, J. M. (2009). Functional, genetic and chemical characterization of biosurfactants produced by plant growthpromoting Pseudomonas putida 267. J. Appl. Microbiol. 107, 546-556. doi: 10.1111/j.1365-2672.2009.04244.x

Kuiper, I., Lagendijk, E. L., Pickford, R., Derrick, J. P., Lamers, G. E. M., Thomas-Oates, J. E., et al. (2004). Characterization of two Pseudomonas putida lipopeptide biosurfactants, putisolvin I and II, which inhibit biofilm formation and break down existing biofilms. Mol. Microbiol. 51, 97-113. doi: 10.1046/j.1365-2958.2003.03751.x

Lundberg, D. S., Lebeis, S. L., Paredes, S. H., Yourstone, S., Gehring, J., Malfatti, S., et al. (2012). Defining the core Arabidopsis thaliana root microbiome. Nature 488, 86-90. doi: 10.1038/nature 11237

Marshall, K., Joint, I., Callow, M. E., and Callow, J. A. (2006). Effect of marine bacterial isolates on the growth and morphology of axenic plantlets of the green alga Ulva linza. Microb. Ecol. 52, 302-310. doi: 10.1007/s00248-006-9060-x

Mendes, R., Kruijt, M., de Bruijn, I., Dekkers, E., van der Voort, M., Schneider, J. H. M., et al. (2011). Deciphering the rhizosphere microbiome for diseasesuppressive bacteria. Science 332, 1097-1100. doi: 10.1126/science.1203980
Mercado-Blanco, J., and Bakker, P. A. H. M. (2007). Interactions between plants and beneficial Pseudomonas spp.: exploiting bacterial traits for crop protection. Antonie Van Leeuwenhoek 92, 367-389. doi: 10.1007/s10482-007-9167-1

Ortiz-Castro, R., Díaz-Pérez, C., Martínez-Trujillo, M., del Río, R. E., CamposGarcía, J., and López-Bucio, J. (2011). Transkingdom signaling based on bacterial cyclodipeptides with auxin activity in plants. Proc. Natl. Acad. Sci. U.S.A. 108, 7253-7258. doi: 10.1073/pnas.1006740108

Patel, H. K., Suárez-Moreno, Z. R., Degrassi, G., Subramoni, S., González, J. F., and Venturi, V. (2013). Bacterial LuxR solos have evolved to respond to different molecules including signals from plants. Front Plant Sci 4:447. doi: 10.3389/fpls.2013.00447

Pernet, E., Guillemot, L., Burgel, P.-R., Martin, C., Lambeau, G., SermetGaudelus, I., et al. (2014). Pseudomonas aeruginosa eradicates Staphylococcus aureus by manipulating the host immunity. Nat. Commun. 5, 5105. doi: $10.1038 /$ ncomms6105

Rahme, L. G., Ausubel, F. M., Cao, H., Drenkard, E., Goumnerov, B. C., Lau, G. W., et al. (2000). Plants and animals share functionally common bacterial virulence factors. Proc. Natl. Acad. Sci. U.S.A. 97, 8815-8821. doi: 10.1073/pnas.97.16.8815

Rahme, L. G., Tan, M. W., Le, L., Wong, S. M., Tompkins, R. G., Calderwood, S. B., et al. (1997). Use of model plant hosts to identify Pseudomonas aeruginosa virulence factors. Proc. Natl. Acad. Sci. U.S.A. 94, 13245-13250.

Rosenberg, E., Koren, O., Reshef, L., Efrony, R., and Zilber-Rosenberg, I. (2007). The role of microorganisms in coral health, disease and evolution. Nat. Rev. Microbiol. 5, 355-362. doi: 10.1038/nrmicro1635

Sana, T. G., Baumann, C., Merdes, A., Soscia, C., Rattei, T., Hachani, A., et al. (2015). Internalization of pseudomonas aeruginosa strain PAO1 into epithelial cells is promoted by interaction of a T6SS effector with the microtubule network. MBio 6:e0712-15. doi: 10.1128/mBio.00712-15

Saraswati, S., and Sitaraman, R. (2014). Aging and the human gut microbiota-from correlation to causality. Front Microbiol 5:764. doi: 10.3389/fmicb.2014.00764

Venturi, V. (2006). Regulation of quorum sensing in Pseudomonas. FEMS Microbiol. Rev. 30, 274-291. doi: 10.1111/j.1574-6976.2005.00012.x

Whiteside, M. D., Winsor, G. L., Laird, M. R., and Brinkman, F. S. L. (2013). OrtholugeDB: a bacterial and archaeal orthology resource for improved comparative genomic analysis. Nucleic Acids Res. 41, D366-376. doi: $10.1093 / \mathrm{nar} / \mathrm{gks} 1241$

Winsor, G. L., Lam, D. K. W., Fleming, L., Lo, R., Whiteside, M. D., Yu, N. Y., et al. (2011). Pseudomonas Genome Database: improved comparative analysis and population genomics capability for Pseudomonas genomes. Nucleic Acids Res. 39, D596-D600. doi: 10.1093/nar/gkq869

Zhao, J., Devaiah, S. P., Wang, C., Li, M., Welti, R., and Wang, X. (2013). Arabidopsis phospholipase D $\beta 1$ modulates defense responses to bacterial and fungal pathogens. New Phytol. 199, 228-240. doi: 10.1111/nph.12256

Conflict of Interest Statement: The author declares that the research was conducted in the absence of any commercial or financial relationships that could be construed as a potential conflict of interest.

Copyright (c) 2015 Sitaraman. This is an open-access article distributed under the terms of the Creative Commons Attribution License (CC BY). The use, distribution or reproduction in other forums is permitted, provided the original author(s) or licensor are credited and that the original publication in this journal is cited, in accordance with accepted academic practice. No use, distribution or reproduction is permitted which does not comply with these terms. 